\title{
Treatment of migraine: a review of disease burden and an update on the therapeutic landscape for pharmacists
}

\author{
Nishil Patel ${ }^{1} \cdot$ Rebecca Barnhart $^{2} \cdot$ Paul Konkol $^{3} \cdot$ Josephine Varda $^{4} \cdot$ Rob Nelson $^{1} \cdot$ Tim Smith $^{5}$
}

Published online: 5 December 2020

(c) The Author(s) 2020 corrected publication 2020

\begin{abstract}
Given the key role of pharmacists as a healthcare resource for patients seeking treatment of headache associated with migraine, this review highlights the burden of migraine, recent advances in preventive migraine therapies, and key takeaways from the most recent migraine management consensus statement. For at least two decades, it has been understood that correct diagnosis of migraine is key to its effective management. Migraine attacks should be treated promptly with acute medications, with preventive treatment for patients with regular, frequent, and/or disabling migraine attacks. Nonetheless, most patients with migraine are still not correctly diagnosed, and do not receive appropriate therapy for acute or preventive treatment of their disease. In addition, patients may be refractory to or unable to tolerate traditional oral preventive treatments, leading to underutilization of preventive treatment and subsequent reliance on acute treatment. Overuse of acute medications is associated with increased risk of progression from episodic to chronic migraine and development of medication overuse headache; therefore, pharmacists should counsel patients receiving over-the-counter or prescription acute migraine medications on when to seek options for preventive treatment to help avoid medication overuse. Pharmacists are well-positioned to identify those patients who would benefit from physician referral for further assessment and treatment with preventive therapy. They also have an important role in educating patients on the benefits of preventive medications, and realistic expectations of treatment outcomes.
\end{abstract}

\section{Background}

The recent emergence of novel therapies has expanded the tools and options for clinicians to treat migraine [1]. Before the introduction of monoclonal antibodies targeting the calcitonin gene-related peptide (CGRP) pathway in 2018 [2], it had been $>25$ years since sumatriptan, a therapy developed specifically for the acute treatment of migraine, was approved by the US Food and Drug Administration (FDA)

Nishil Patel

npatel05@amgen.com

1 Amgen Inc., US Medical Affairs, Thousand Oaks, CA, USA

2 Ambulatory Care Pharmacy Services, UC Health University of Colorado Hospital, Aurora, CO, USA

3 Pharmacy Specialty Services, SSM Health Pharmacy, Madison, WI, USA

4 Department of Pharmacy, Diamond Headache Unit at AMITA Health Saint Joseph Hospital Chicago, Chicago, IL, USA

5 StudyMetrix Research, LLC, Saint Peters, MO, USA
[3], and a decade since FDA approval of a preventive medication (onabotulinumtoxinA) for chronic migraine (CM) [4]. Further, prior to the development of monoclonal antibodies targeting the CGRP pathway, all medications used for preventive treatment of migraine had been initially approved for other indications [1].

The purpose of this review is to highlight the burden of migraine and unmet need in appropriate migraine management, describe recent advances in preventive migraine therapies, and highlight key takeaways from the most recent migraine management consensus statement [5] to provide pharmacists with an overview of the current expert opinion on the management of migraine. The information in this review is applicable to pharmacists in all pharmacy settings, such as community, ambulatory care, specialty, and clinical pharmacists. Nonetheless, the information may be more readily incorporated in the practices of community and ambulatory pharmacists because migraine is primarily addressed as an outpatient. 


\section{Migraine: burden of disease}

Worldwide migraine affects $>10 \%$ of the world's population $(\approx 1.04$ billion individuals $)$ and is the second leading cause of years-lived-with-disability (YLD) [6]. In the USA, migraine is the fifth leading cause of YLD [6]. The American Migraine Prevalence and Prevention study (AMPP) found the prevalence of migraine was $\approx 12 \%$, that migraine is $2-3$ times more common in women than men, and that it peaks in mid-life (age 30-39 years) [7].

Migraine, a relapsing and remitting disease, presents with a variable frequency of attacks [8]. Patients diagnosed with migraine with $\geq 15$ headache days per month ( $\geq 8$ of which meet migraine diagnostic criteria, including lasting 4-72 h when untreated or unsuccessfully treated) for $\geq 3$ months are classified as having $\mathrm{CM}$; those with $<15$ headache days per month are considered to have episodic migraine (EM) [9]. However, due to the high level of variability in monthly headache days for individual patients, classification is not straightforward and patients can move between EM and CM [8]. Between 2.5 and 14\% of patients with EM transition to CM annually [10-12]; factors such as acute medication overuse, ineffective acute treatment, obesity, insomnia, snoring, and stressful life events are associated with an increased risk of transition $[10,12-14]$.
Despite the categorical distinction of EM and CM based on monthly headache days [9], the impact of migraine is not as distinct. To enable a broader understanding of the impact of migraine beyond number of headache days and an understanding of the disease from a patient's perspective, a range of patient-reported outcome (PRO) assessments have been developed, each with unique advantages and disadvantages (Table 1) [15-23]. Two of the most common PROs are the Headache Impact Test-6 $\left(\right.$ HIT- $\left.{ }^{\mathrm{TM}}\right)[16,17]$ and Migraine Disability Assessment Scale (MIDAS) [18, 19]. The Migraine-Specific Quality-ofLife Questionnaire (MSQ) is another validated PRO assessment used specifically in migraine [20]. Newer instruments such as the Migraine Physical Function Impact Diary (MPFID) [21, 23] and the Migraine Functional Impact Questionnaire (MFIQ) [22, 23] have shorter recall times reflecting the FDA guidance [24]. These PRO instruments have painted a consistent picture of the substantial burden of migraine [25-30].

In addition to the personal and societal burden of migraine, migraine has a high burden on healthcare systems. It has been reported that there is an emergency room visit for headache or migraine every $10 \mathrm{~s}$ in the USA, representing $\approx 1.2$ million visits annually for acute migraine attacks [31], and a substantive burden on the healthcare system $[15,32,33]$.

Table 1 Overview of patient-reported outcome (PRO) assessment tools [15]

\begin{tabular}{|c|c|c|c|}
\hline PRO & Key features & Advantages & Disadvantages \\
\hline $\begin{array}{l}\text { HIT-6 [16, } \\
17]\end{array}$ & $\begin{array}{l}\text { Assesses impact of headache on social } \\
\text { and role functioning, pain severity, } \\
\text { fatigue and mood over previous } \\
4 \text { weeks }\end{array}$ & $\begin{array}{l}\text { Accurate across all headache sever- } \\
\text { ity levels in clinical research and } \\
\text { clinical practice; only contains } \\
6 \text { questions so easy to complete }\end{array}$ & Not migraine specific \\
\hline MIDAS [18] & $\begin{array}{l}\text { Assesses time lost due to migraine } \\
\text { work/school, household work, family/ } \\
\text { leisure/social activities over previous } \\
3 \text { months }\end{array}$ & $\begin{array}{l}\text { Reliable, accurate and easy to use } \\
\text { in research and clinical practice; } \\
\text { migraine specific }\end{array}$ & $\begin{array}{l}\text { Only covers the moderate through to severe } \\
\text { spectrum of migraine; some consider too } \\
\text { heavily weighted toward headache frequency }\end{array}$ \\
\hline MSQ [20] & $\begin{array}{l}\text { Assesses the degree activities are pre- } \\
\text { vented or restricted by migraine, and } \\
\text { emotional functioning over previous } \\
4 \text { weeks }\end{array}$ & Reliable, with construct validity & $\begin{array}{l}\text { May be too complex to use routinely in } \\
\text { clinical practice }\end{array}$ \\
\hline $\begin{array}{l}\text { MPFID [21, } \\
23]\end{array}$ & $\begin{array}{l}\text { Assesses the impact of migraine on } \\
\text { everyday activities and physical } \\
\text { impairment over previous } 24 \mathrm{~h}\end{array}$ & $\begin{array}{l}\text { Patient input into the conceptualiza- } \\
\text { tion of tool; designed to comply } \\
\text { with FDA guidelines for PROs }\end{array}$ & $\begin{array}{l}\text { Ability to offer a complete picture of migraine } \\
\text { is unclear }\end{array}$ \\
\hline $\begin{array}{l}\text { MFIQ [22, } \\
23]\end{array}$ & $\begin{array}{l}\text { Assesses the impact of migraine on } \\
\text { physical, social and emotional func- } \\
\text { tion, and on everyday activities over } \\
7 \text { days }\end{array}$ & $\begin{array}{l}\text { 7-day recall may capture variability } \\
\text { of impact, without the burden of } \\
\text { daily assessments }\end{array}$ & $\begin{array}{l}\text { Ongoing analysis of tool underway to develop } \\
\text { responder definitions }\end{array}$ \\
\hline
\end{tabular}

HIT-6 6-item headache impact test; MFIQ Migraine Functional Impact questionnaire; MIDAS Migraine Disability Assessment questionnaire; $M S Q$ Migraine-Specific Quality of Life Questionnaire 


\section{Unmet medical need in migraine}

In addition to characterizing the population affected by severe migraine, the AMPP study illustrated the unmet medical need experienced by patients with migraine, with $\approx 44 \%$ of people with migraine having never received a medical diagnosis [34]. Additionally, patients with a migraine diagnosis were shown to have extreme difficulty accessing both acute and preventive treatment $[35,36]$. An exploratory analysis from the AMPP study found that only $26 \%$ of the original EM cohort successfully overcame all three barriers (consultation, diagnosis, and treatment) [35]. Data from patients with CM suggest even more challenges, with the Chronic Migraine Epidemiology and Outcomes Study (CaMEO) reporting $<5 \%$ of patients with CM successfully traversed the same three barriers, with difficulties particularly in seeking a consultation and receiving an accurate diagnosis of CM [36]. Furthermore, of those who consulted a healthcare professional and were accurately diagnosed, less than half received preventive and acute treatment [36]. More recent data confirm migraine remains underdiagnosed and undertreated [29].

Since most migraine patients do not receive a correct diagnosis and appropriate care, there is greater reliance on over-the-counter (OTC) medications and prescription analgesics to manage symptoms of migraine headache and pain. The AMPP study found $49 \%$ of patients exclusively used OTC medications for acute treatment of migraine; $29 \%$ sometimes used OTC medications and sometimes used prescription medications [34]. While some OTC acute medications may be useful for migraine, patients who use acute medications too frequently can develop medication overuse headache $(\mathrm{MOH}) . \mathrm{MOH}$ is a secondary headache occurring on $\geq 15$ days per month in patients with underlying headache disorders, such as migraine, as a consequence of regular overuse of acute headache therapies (i.e., $\geq 10$ days per month of ergotamine, triptans, opioids, combination analgesics, or $\geq 15$ days per month of acetaminophen [paracetamol], NSAIDs, or acetylsalicylic acid) for $>3$ months [9, 37]. In December 2017, the FDA issued a final decision requesting the inclusion of a new warning on all OTC migraine headache medications (e.g., Excedrin Migraine) to ensure patients were informed that "headaches may worsen" if the OTC headache medication "is used for 10 or more days per month" [38]. It is important that pharmacists inform patients of label warnings when recommending acute OTC headache therapies, advise on the importance of seeking medical guidance, and counsel against overuse of prescribed acute medications. This is especially important with opioids, as $\approx 20 \%$ of patients with migraine currently use opioids or are administered opioids in emergency room encounters for migraine [39, 40].

\section{Preventive therapy for migraine}

\section{Non-migraine specific therapies}

Prior to the approval of monoclonal antibodies targeting the CGRP pathway, onabotulinumtoxinA was the only drug approved by the FDA specifically for the preventive treatment of CM [4]. Other FDA-approved medications that are used for the prevention of migraine headache include topiramate, propranolol, divalproex sodium and timolol (Table 2) [41-56]. Some of these medications were not studied specifically in patients with CM, as studies were conducted before the definition of CM was fully established. Furthermore, none of the current oral preventive options were developed specifically for migraine; in addition, many treatments are used off-label for the prevention of migraine headaches [5]. For example, valproate sodium and metoprolol are rated by the American Headache Society (AHS) as having established efficacy for treatment of migraine despite lacking an FDA indication for this condition [5]. Preventive therapy is initiated based on frequency of migraine attacks as well as overall severity and disability of disease (Fig. 1) [5]. The AHS consensus statement "The American Headache Society Position Statement On Integrating New Migraine Treatments Into Clinical Practice" recommends that preventive treatment be considered for patients with 2 monthly headache days with moderate disability, 3 monthly headache days with some disability, and 4 or 5 monthly headache days without any disability. In contrast, preventive treatment should be offered to all patients with $\geq 3$ monthly headache days with severe disability, $\geq 4$ monthly headache days with some disability, and $\geq 6$ monthly headache days with no disability [5]. Goals of preventive therapy include reducing frequency, duration, and severity of migraine attacks, enhancing responsiveness to migraine-specific headache therapy, avoiding escalation in use of and reliance on acute treatment, improving ability to function, reducing disability, improving health-related quality of life (HR-QoL), and reducing healthcare costs $[5,57]$.

Only $12 \%$ of patients in the AMPP population used preventive therapy; another $17 \%$ were coincidental users (i.e., used a known preventive medication, but not reportedly for prevention of migraine) [34]. Based on expert consensus at that time [7], which was the precursor to, and mirrors, current guidelines [5], preventive therapy could have been at least considered for $\approx 40 \%$ of these patients with migraine 
Table 2 Summary of preventive treatments available for migraine (level A or B evidence) [5]

Treatments Key counselling notes $\quad$ Recommended dosage $^{\mathrm{a}} \quad$ Duration of adequate trial $^{\mathrm{b}}$

\section{FDA approved}

\section{Antiepileptic drugs}

Divalproex sodium [41] Risk of hepatotoxicity, ensure liver testing throughout treatment and advise pts that symptoms such as nausea, vomiting, abdominal pain requires medical assessment; avoid in women of childbearing age, not using reliable birth control; advise pts and family to report signs of depression or changes in mood to their healthcare provider

Topiramate [42]

Avoid in women of childbearing age, not using reliable birth control; avoid alcohol within $6 \mathrm{~h}$ of dose; advise pts and family to report signs of depression or changes in mood to their healthcare provider; seek immediate medical attention for visual disturbances or periorbital pain

\section{$\beta$-blockers}

Propranolol [43]

Use with caution in pts with renal or hepatic impairment, or with CHF; advise on potential risk of hypersensitivity; reduce dose gradually over at least 3 wks if discontinuing therapy

Timolol [44]

Use with caution in pts with cardiovascular disease; avoid during pregnancy if possible; advise on the potential risk of hypersensitivity

\section{Inhibitors of the CGRP pathway}

Erenumab [45]

Provide advice on use of the SC autoinjector; advise on potential risk of constipation, injection site pain, and hypertension or worsening of pre-existing hypertension; safety in pregnancy not yet known

Galcanezumab [46]

Provide advice on use of the SC prefilled pen and syringe; advise on potential risk of hypersensitivity reactions and injection site reactions; safety in pregnancy not yet known

Fremanezumab [47] Provide advice on use of the SC prefilled syringe and autoinjector; advise on potential risk of hypersensitivity reactions and injection site reactions; safety in pregnancy not yet known

Eptinezumab [48]

\section{Others}

OnabotulinumtoxinA (approved for CM

Medications with es Valproate sodium [50]

Advise on potential risk of hypersensitivity reactions and stuffy nose and scratchy throat; safety in pregnancy not yet known

Advise to seek medical advice if swallowing, speaking or breathing difficulties develop only) [49]
For the extended release product:

Wk 1: $500 \mathrm{mg}$ daily

Wk 2 onwards: $1000 \mathrm{mg}$ daily

Dose titration as follows:

Wk 1: $25 \mathrm{mg}$ daily

Wk 2: $50 \mathrm{mg}$ daily

Wk 3: $75 \mathrm{mg}$ daily

Wk 4: 100 mg daily

Initial dose: $80 \mathrm{mg}$ daily in divided doses

Usual effective dose:

160-240 mg daily

10-20 mg daily

$70 \mathrm{mg}$ SC q1mo (some pts may benefit from $140 \mathrm{mg}$ q1mo)

Loading dose of $240 \mathrm{mg} \mathrm{SC}$, then $120 \mathrm{mg} \mathrm{SC} \mathrm{q1mo}$

dose

Either: $225 \mathrm{mg} \mathrm{SC}$ q1mo, or $675 \mathrm{mg}$ SC q3mo

When switching dosage, administer new dose on next scheduled day

$100 \mathrm{mg}$ as IV infusion q3mo (may $\uparrow$ to $300 \mathrm{mg}$ )

155 U IM across 7 specific head/neck muscle areas dose dose dose
At least 8 wks after TT reached

At least 8 wks after TT reached

At least 8 wks after TT reached

At least 8 wks after TT reached

At least 3 mo after initial

At least 3 or 6 mo after initial dose for $\mathrm{q} 1 \mathrm{mo}$ and $\mathrm{q} 3 \mathrm{mo}$ administration, respectively

At least 6 mo after initial

At least 6 mo after initial

At least 8 wks after TT reached and advise on symptoms such as malaise, lethargy, anorexia and vomiting; risk of pancreatitis with similar symptoms; women of childbearing potential should use effective contraception

Metoprolol [51]
500-2000 mg daily

100-200 mg daily
Contraindicated in pts with sinus bradycardia or cardiac failure; use with caution in pts with impaired hepatic function; hypersensitivity may occur
At least 8 wks after TT reached 
Table 2 (continued)

\begin{tabular}{|c|c|c|c|}
\hline Treatments & Key counselling notes & Recommended dosage $^{a}$ & Duration of adequate trial ${ }^{\mathrm{b}}$ \\
\hline \multicolumn{4}{|c|}{ Medications with probable efficacy [5], not FDA-approved for migraine prevention } \\
\hline Amitriptyline [52] & $\begin{array}{l}\text { Advise pts and family to report signs of depression } \\
\text { or changes in mood to their healthcare provider; } \\
\text { consider the possibility of drug interactions via the } \\
\text { cytochrome P450 pathway }\end{array}$ & 10-200 mg daily & $\begin{array}{l}\text { At least } 8 \text { wks after TT } \\
\text { reached }\end{array}$ \\
\hline Venlafaxine [53] & $\begin{array}{l}\text { Advise pts and family to report signs of depression or } \\
\text { changes in mood to their healthcare provider; dosage } \\
\text { adjustment in renal and hepatic impairment; avoid } \\
\text { alcohol }\end{array}$ & $75-225 \mathrm{mg}$ daily & $\begin{array}{l}\text { At least } 8 \text { wks after TT } \\
\text { reached }\end{array}$ \\
\hline Atenolol [54] & $\begin{array}{l}\text { Use with caution in pts with renal or hepatic impair- } \\
\text { ment, or with CHF; advise on potential risk of } \\
\text { hypersensitivity; reduce dose gradually if discontinu- } \\
\text { ing therapy }\end{array}$ & 50-200 mg daily & $\begin{array}{l}\text { At least } 8 \text { wks after TT } \\
\text { reached }\end{array}$ \\
\hline Nadolol [55] & $\begin{array}{l}\text { Use with caution in pts with renal impairment, or with } \\
\text { CHF; reduce dose gradually over } 1-2 \text { wks if discon- } \\
\text { tinuing therapy }\end{array}$ & $20-160 \mathrm{mg}$ daily & $\begin{array}{l}\text { At least } 8 \text { wks after TT } \\
\text { reached }\end{array}$ \\
\hline
\end{tabular}

CGRP calcitonin gene-related peptide, $C H F$ congestive heart failure, $C M$ chronic migraine, $I M$ intramuscular; $I V$ intravenous; $m o$ month, $p t$ patient, qxmo every $x$ mo, $S C$ subcutaneous; $T T$ therapeutic target, $w k$ week

${ }^{a}$ For drugs which are not specifically approved for the prevention of migraine, daily dose is from Schwedt [56]

${ }^{\mathrm{b}} \mathrm{A} 50 \%$ reduction in monthly headache days is considered to represent a response to treatment; however, other factors such as pain severity, level of disability and functional capacity should be taken in to account; pts demonstrating a partial response at the time of assessment may warrant continuation of the preventive treatment and further assessment

(i.e., considered for $13 \%$ of patients and offered to $26 \%$ of patients) [7].

Discontinuation rates are high for patients who initiate oral preventive therapy. The Second International Burden of Migraine Study (IBMS-II) assessed preventive therapy (i.e., antidepressants, anti-epileptics, $\beta$-blockers, and calcium channel blockers) patterns in 1165 patients with either EM $(n=672)$ or CM $(n=493)$ from six countries [58]. Discontinuation of $\geq 1$ preventive medication was reported by $24 \%$ and $41 \%$ of EM and CM respondents, respectively. Patientreported reasons for discontinuation were lack of efficacy (>40\%) and adverse events (> 35\%) [58], highlighting an unmet need for improved preventive therapies and possibly unrealistic patient expectations for preventive therapy. Fewer than $15 \%$ of patients discontinued therapy because their symptoms had resolved sufficiently to warrant cessation [58]. Similarly, a recent analysis of persistence with preventive migraine medications over $2-5$ years using data from the IBM Marketscan ${ }^{\circledR}$ database (IBM, Armonk, New York) and Medicare databases found that only $10 \%$ of 147,832 migraine patients maintained preventive therapy (mean time of persistence 3.6 years); of the $90 \%$ of patients who were nonpersistent, mean time to nonpersistence was 186.4 days [59]. Furthermore, $95 \%$ of patients received acute migraine medications during the study follow-up period. The most frequently used acute migraine medication class was opioids (strong and weak opioids, including NSAID and opioid combination drugs, $77 \%$ ), with a mean of 13.6 prescription claims per patient [59]. Thus, current evidence demonstrates that patients are being treated acutely with non-preferred acute migraine medications (i.e., opioids) and are being undertreated with preventive therapies.

\section{Calcitonin gene-related peptide inhibitors}

The recent approval of monoclonal antibodies targeting the CGRP pathway for prevention of migraine in adults has expanded and improved available options for migraine treatment. CGRP, a vasodilatory neuropeptide with multiple sites of action, has been identified as a key player in migraine pathophysiology through its involvement in nociception and sensitization of peripheral and central neurons in the trigeminovascular system [60]. CGRP is also associated with neurogenic inflammation and pronociceptive activity [61]. CGRP levels in the jugular venous blood are elevated in patients with migraine, increase during migraine attacks, and can induce migraine-like headaches in people susceptible to migraine $[60,62,63]$. Sumatriptan has been shown to normalize plasma CGRP levels, reinforcing the role of CGRP in migraine [64].

Following recognition of the role of CGRP in the pathogenesis of migraine, small-molecule antagonists of the CGRP receptor (known as gepants) were developed and found to be effective for the acute and preventive treatment of migraine [65]. The early development of these smallmolecule inhibitors for preventive treatment was stopped 


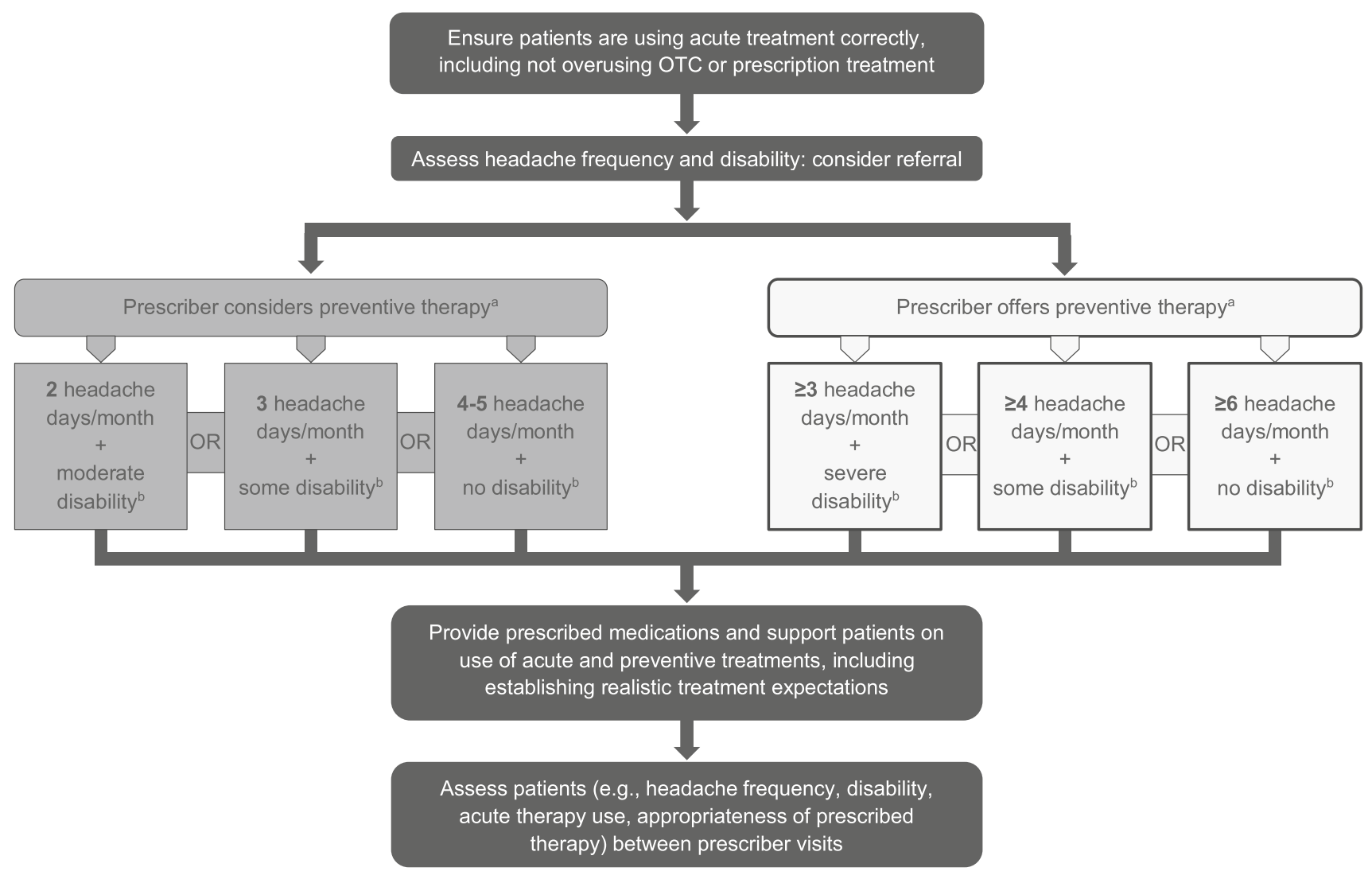

Fig. 1 Pharmacist role, unless otherwise indicated, in identifying and supporting patients likely to benefit from preventive treatment. ${ }^{a}$ Recommendations from the American Headache Society Consen-

largely due to hepatic toxicity [65]; however, ubrogepant and rimegepant have recently been approved for acute treatment of migraine [66, 67]. In the interim, monoclonal antibodies against the CGRP receptor (erenumab) or CGRP ligand (galcanezumab, fremanezumab, and eptinezumab) were approved for preventive treatment of migraine $[48,68]$. The long half-life of these preventive medications enables monthly subcutaneous administration for erenumab, galcanezumab and fremanezumab (with an every-3-month administration option for fremanezumab) [68] and every-3-month intravenous administration for eptinezumab [48].

Key clinical trial results for the monoclonal antibodies targeting the CGRP pathway currently approved or under clinical development are provided in Table 3 [47, 69-75]. In summary, CGRP-inhibitors, whether they directly interact with the receptor or the ligand, significantly reduced monthly migraine days, significantly increased the proportion of patients achieving a $\geq 50 \%$ reduction in monthly migraine days, and significantly reduced monthly acute migraine-specific medication use days compared with placebo in patients with CM and EM. In addition to those monoclonal antibodies that are currently approved, oral sus Statement [5]. ${ }^{\mathrm{b}}$ Disability as assessed by the Migraine Disability Assessment (MIDAS) tool. OTC over-the-counter.

small-molecule CGRP receptor antagonists are also being evaluated for the prevention of migraine [68].

\section{Migraine treatment guidelines from the AHS and AAN}

The leading organizations in the US for headache treatment and management are the American Academy of Neurology (AAN) and AHS. In 2000, these two organizations were joined by five other national organizations to form the US Headache Consortium, which developed the first consensus guidelines for acute treatment and prevention of migraine [57]. Key to the management of migraine is accurate diagnosis and the subsequent education of patients about their condition and treatment, including establishing realistic treatment expectations, and encouraging patients to identify and avoid migraine triggers [57]. For acute treatment, these early guidelines recommended treating attacks promptly with an effective acute migraine-specific treatment, selecting a non-oral medication with patients presenting with migraine associated with severe nausea and vomiting, identifying a self-administered "rescue" 
medication for use if the initial acute medication was ineffective. To prevent $\mathrm{MOH}$, the use of acute therapy for $>2$ headache days per week was cautioned against [57]. For preventive treatment, it was recommended to use medications with the best evidence while taking comorbidities into account, initiate therapy at the lowest effective dose, give each drug an adequate (2-3 month) trial, monitor treatment response through a headache diary, and to consider the role of concurrent non-pharmacologic treatment [57]. These overarching treatment principles remain valid today and underpin current guidelines.

The AAN and AHS have worked together to update guidelines for preventive treatment of EM to include data on the safety and efficacy of newer preventive therapies [76], while the AHS has used the AAN protocols to update acute treatment guidelines [77]. In December 2018, AHS, building on earlier work of the US Headache Consortium, provided a position statement to update previous recommendations, providing greater specificity regarding criteria for preventive treatment (Table 2) and outlining the emerging role of inhibitors of the CGRP pathway in preventive treatment (Fig. 2) [5]. The AHS also reviewed and updated current guidelines for acute treatment, confirming acute treatment goals and considerations and updating advice on the effectiveness of available acute treatments (Table 4) [5]; since that time ubrogepant [66], lasmiditan [78] and rimegepant [67] have been approved for acute treatment of migraine. The AHS guidelines provide increased clarity on the importance of preventive treatment in patients with severe, disabling or frequent migraine attacks and in those who are intolerant of or nonresponsive to acute treatment [5].

\section{Role of pharmacists in management of patients with migraine}

Pharmacists are well-placed to support patients with migraine, because they are extremely accessible healthcare professionals, with patients commonly seeking their advice [79]. Indeed, one survey found that $97 \%$ of community pharmacists made $\geq 1$ OTC recommendation each day for the treatment of headache [80], with the most recent Pharmacy Times OTC survey estimating that pharmacists in the USA

Table 3 Pivotal studies of monoclonal antibodies targeting the CGRP pathway ${ }^{\mathrm{a}}$

\begin{tabular}{|c|c|c|c|c|}
\hline CGRP pathway inhibitor & Trial ID (trial name) & $\begin{array}{l}\text { Change in MMDs } \\
\text { from } \mathrm{BL}\end{array}$ & $\begin{array}{l}50 \% \text { responder } \\
\text { rate }(\%)\end{array}$ & $\begin{array}{l}\text { Change in monthly } \\
\text { AMSM days from } \\
\text { BL }\end{array}$ \\
\hline \multicolumn{5}{|l|}{ Episodic migraine } \\
\hline Erenumab 70 mg q1mo [69] & NCT02456740 (STRIVE) & $-3.2(0.2)^{* *}$ & $43.3 * *$ & $-1.1(0.1)^{* *}$ \\
\hline Erenumab 140 mg q1mo [69] & NCT02456740 (STRIVE) & $-3.7(0.2)^{* *}$ & $50.0 * *$ & $-1.6(0.1)^{* *}$ \\
\hline Galcanezumab $120 \mathrm{mg} \mathrm{q} 1 \mathrm{mo}[70]^{\mathrm{b}}$ & NCT02614183 (EVOLVE-1) & $-4.7 * *$ & $62.3 * *$ & $-4.0 * *$ \\
\hline Galcanezumab 240 mg q1mo [70] & NCT02614183 (EVOLVE-1) & $-4.6 * *$ & $60.9 * *$ & $-3.8^{* *}$ \\
\hline Fremanezumab 225 mg q1mo [47] & NCT02629861 & $-3.7 * *$ & $47.7 * *$ & $-3.0 * *$ \\
\hline Fremanezumab 675 mg q3mo [47] & NCT02629861 & $-3.4 * *$ & $44.4 * *$ & $-2.9 * *$ \\
\hline Eptinezumab 100 mg q3mo [71] & NCT02559895 (PROMISE 1) & $-3.9 *$ & $49.8^{*}$ & NR \\
\hline Eptinezumab 300 mg q3mo [71] & NCT02559895 (PROMISE 1) & $-4.3 * *$ & $56.3 * *$ & NR \\
\hline \multicolumn{5}{|l|}{ Chronic migraine } \\
\hline Erenumab 70 mg q1mo [72] & NCT02066415 & $-6.6(0.4)^{* * *}$ & $40 * *$ & $-3.5(0.3)^{* * *}$ \\
\hline Erenumab 140 mg q1mo [72] & NCT02066415 & $-6.6(0.4)^{* * *}$ & $41 * * *$ & $-4.1(0.3)^{* * *}$ \\
\hline Galcanezumab 120 mg q1mo [73] & NCT02614261 (REGAIN) & $-4.8(0.4)^{* *}$ & $27.6 * *$ & $-4.7(0.4)^{* *}$ \\
\hline Galcanezumab 240 mg q1mo [73] & NCT02614261 (REGAIN) & $-4.6(0.4)^{* *}$ & $27.5 * *$ & $-4.3(0.4)^{* *}$ \\
\hline Fremanezumab 225 mg q1mo [74] & NCT02621931 & $-5.0(0.4)^{* *}$ & $41 * *$ & $-4.2(0.3)^{* *}$ \\
\hline Fremanezumab 675 mg q3mo [74] & NCT02621931 & $-4.9(0.4)^{* *}$ & $38^{* *}$ & $-3.7(0.3)^{* *}$ \\
\hline Eptinezumab 100 mg q3mo [75] & NCT02974153 (PROMISE 2) & $-7.7 * * *$ & $57.6^{* * *}$ & $-3.3 * * *$ \\
\hline Eptinezumab 300 mg q3mo [75] & NCT02974153 (PROMISE 2) & $-8.2 * * *$ & $61.4 * * *$ & $-3.5 * * *$ \\
\hline
\end{tabular}

$A M S M$ acute migraine-specific medication, $B L$ baseline, $C G R P$ calcitonin gene-related peptide, $I D$ identification from the ClinicalTrials.gov website, $M M D$ monthly migraine day, $N R$ not reported, qxmo every x months

$* p<0.05, * * p<0.001$, ***p $<0.0001$ vs placebo

${ }^{a}$ Data may have been assessed differently in each trial and may not be directly comparable head-to-head

${ }^{\mathrm{b}} \mathrm{Galcanezumab} 300 \mathrm{mg}$ q1mo is also indicated for the treatment of episodic cluster headache 
make $\approx 1.9$ million OTC recommendations for headache per month, with $\approx 800,000$ specifically for migraine [81, 82].

Pharmacists have the knowledge base to support patients with migraine, with the majority of the headache curricula in PharmD programs in the USA teaching information consistent with migraine treatment guidelines [83]. Residency programs also provide important information on drug selection and patient education [83]. The specific role of a pharmacist in the management of patients with migraine will, however, vary depending on their practice setting and patient relationships.

First and foremost, the community-based pharmacist is the only healthcare professional that some patients with migraine visit $[84,85]$. Up to one-third of those with migraine do not consider migraine a disease and, therefore, do not consult a primary-care physician [85]. Screening tools have been developed to assist pharmacists to identify patients with possible migraine based on a simple 4-question algorithm querying the percentage of headaches prohibiting normal activities and/or accompanied by vomiting, headache-free days per month, symptoms that accompany headaches, and the OTC products that have been tried [86]. In particular, the pharmacist can identify those who, based on headache frequency and disability level, would benefit most from physician referral and possible preventive treatment (Fig. 1) [87, 88].

In patients managed on OTC medication alone, the pharmacist has an opportunity to assess treatment outcome and

Prescribed by licensed medical practitioner

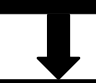

Patient is $\geq 18$ years of age

Diagnosis of ICHD-3 migraine with or without aura ( $\geq 4$ monthly headache days)
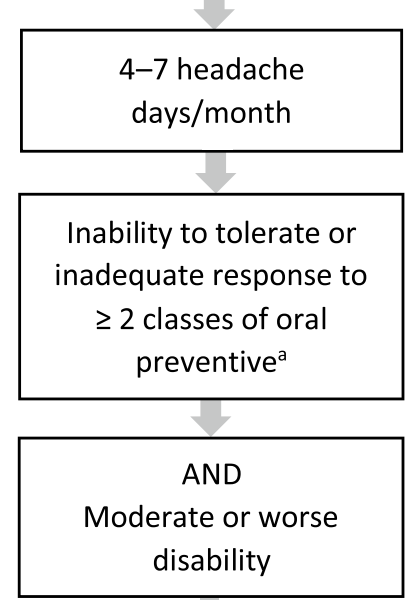
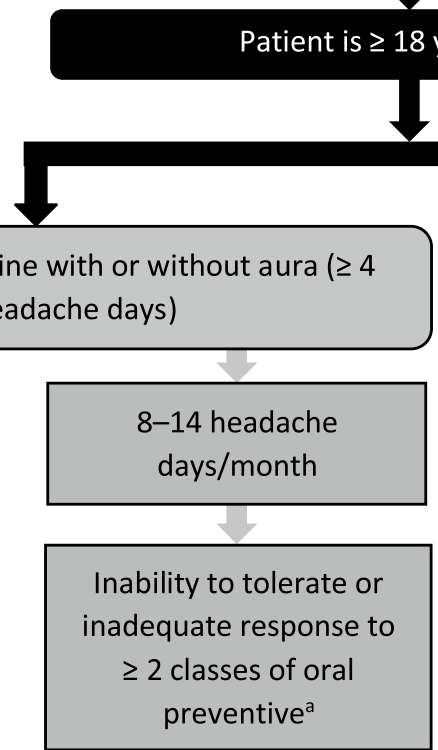

Diagnosis of ICHD-3 chronic migraine

\section{Consider CGRP monoclonal antibody}

therapy

Fig. 2 Overview of role of inhibitors of the CGRP pathway for prevention of migraine as suggested by the American Headache Soci-

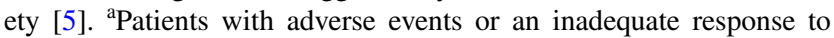
a 6-week trial of topiramate, divalproex sodium/valproate sodium, $\beta$-blocker, tricyclic antidepressant, serotonin-norepinephrine reuptake inhibitor or any other Level A or Level B treatments, per the Ameri- can Academy of Neurology-American Headache Society guidelines. ${ }^{b}$ Patients with adverse events or an inadequate response to a minimum of two quarterly injections (6 months of therapy). CGRP calcitonin gene-related peptide, ICHD-3 International Classification of Headache Disorders, 3rd Edition. 
discuss possible use of preventive treatment with those who do not achieve acceptable headache relief [88]. Importantly, patients need to understand the risks of overusing acute medication [86, 88-90]. With a unique view of both OTC and prescribed medicines, the community pharmacist is well-placed to detect medication overuse [85]. Pharmacists can also counsel patients to avoid lifestyle factors that may contribute to disease progression.

For all patients, pharmacists have a role in educating patients regarding realistic treatment expectations and providing drug-specific counseling to optimize adherence [88] For patients on prescription medications, in particular, some suggest pharmacists could do more to provide medicationspecific education and advice [87]. The pharmacist may also have a role in providing information on non-pharmacologic

Table 4 Summary of considerations for acute treatment and overview of acute treatments with established efficacy [5]

Treatment considerations for acute treatment

Offer all patients with migraine acute treatment

Use evidence-based acute treatment

Treat at first sign of pain

For patients with severe nausea or vomiting, choose a non-oral route of administration

Subcutaneous or intranasal sumatriptan

Intranasal or intramuscular ketorolac

Subcutaneous or intranasal dihydroergotamine

Rectal administration of antiemetics such as prochlorperazine

Consider tolerability of acute medication and comorbid conditions

NSAIDs cardiovascular and gastrointestinal tolerability

Avoid triptans and ergotamines in patients with coronary artery disease, peripheral vascular disease and uncontrolled hypertension

Consider use of a self-administered rescue treatment

Consider for patients with a history of nonresponse or variable response to their acute treatment

Avoid medication overuse

Advise patients to avoid using acute medications for $>2$ headache days per week

Consider preventive medication for patients with $\geq 6$ monthly headache days (see Table 2)

Acute medications with established efficacy [5]

Triptans

Calcitonin gene-related peptide receptor antagonists (gepants: ubrogepant, rimegepant) ${ }^{\mathrm{a}}$

Ergotamine derivatives

5- $\mathrm{HT}_{1 \mathrm{~F}}$ receptor agonists (ditans: lasmitidan) ${ }^{\mathrm{a}}$

NSAIDs (aspirin, diclofenac, ibuprofen, naproxen)

Opioids (butorphanol ${ }^{\mathrm{b}}$ )

Combination medications

${ }^{a}$ Not approved at the time the AHS consensus statement was developed

${ }^{\mathrm{b}}$ Use is not recommended in migraine treatment options including the identification and avoidance of triggers [91], an important area where pharmacists could have greater input [87].

In patients under the active management of a physician, pharmacists may serve as the medication use specialist, supporting the prescriber in selection of the most appropriate acute or preventive therapy based on patient-specific factors including comorbidities, identifying adverse events and managing drug-related problems, such as potential drugdrug interactions [79]. When working in collaboration with the physician, the pharmacist may also have a role in medication management [79], which in relation to migraine could involve managing the tapering or discontinuation of acute medicines, particularly in patients presenting with $\mathrm{MOH}$ or whose migraines are being managed with opioids or barbiturates [90].

It has been demonstrated that pharmacists can improve the HR-QoL of patients with migraine by providing structured evaluation and counseling in liaison with other healthcare professionals [92]. Given the limited number of boardcertified headache specialists in the USA (i.e., $>39,000$ patients for every specialist) [31] and the recognized shortage of primary care physicians, community-based pharmacists have an increasingly important role in the management of patients with migraine [79].

\section{Conclusions}

More than 39 million Americans have migraine [31], the treatment of which is healthcare resource intensive [32]. Given that pharmacists make $>1$ million migraine-specific treatment recommendations per month, they are uniquely positioned and trained to identify patients with headache and potentially undiagnosed migraine, help patients manage acute migraine symptoms, and recommend referral to primary care physicians or specialists to ensure access to the most appropriate migraine treatment based on the patient's individual needs. Pharmacists are also well-placed to assist patients to understand what outcomes to expect from preventive medication and the importance of maintaining a headache diary. By providing an overview of the burden of disease, barriers to care, current evidence-based treatment recommendations, and highlighting the role for the newest preventive therapies in migraine management, pharmacists have the information to make more informed decisions and better advise patients about the treatment of migraine and, in particular, why, how, and when preventive therapy should be initiated. 


\section{Take home messages}

- Pharmacists are in a position to identify patients with migraine who may benefit from further physician assessment and preventive therapies.

- Pharmacists can educate patients on the benefits of preventive medications for migraine, and what to realistically expect from their treatment.

Acknowledgaments The authors thank Annalise Nawrocki, PhD, CMPP (Amgen Inc., Thousand Oaks, CA, USA) and Lee Hohaia, PharmD, CMPP (ICON, North Wales, PA, USA) for editorial assistance in the preparation of this manuscript.

\section{Declarations}

Funding This manuscript was supported by Amgen, Inc.

Conflicts of interest Nishil Patel: employment with and stock ownership in Amgen Inc. Rebecca Barnhart: no financial support or personal connections that could be perceived to bias her work. Paul Konkol: no financial support or personal connections that could be perceived to bias his work. Josephine Varda: no financial support or personal connections that could be perceived to bias her work. Rob Nelson: employment with and stock ownership in Amgen Inc. Tim Smith: consultant or scientific advisor for Amgen, Biohaven, Impel Neuropharma, Eli Lilly, Lundbeck, Theranica; research support for Allergan, Amgen, Biohaven, Charleston Labs, Eli Lilly, Electrocore, Lundbeck, Novartis, Novo Nordisk, Satsuma, Theranica, Vorso; board member and officer for National Headache Foundation; stock ownership in United Health Group (UNH).

Ethics approval Not applicable.

Consent to participate Not applicable.

Consent for publication Not applicable.

Availability of data and material Not applicable.

Code availability Not applicable.

Author contributions The authors attest that they have participated sufficiently in the conception, design, and writing of this manuscript. The authors take public responsibility for the content and agree to be accountable for the accuracy and integrity of this work.

Open Access This article is licensed under a Creative Commons Attribution-NonCommercial 4.0 International License, which permits any non-commercial use, sharing, adaptation, distribution and reproduction in any medium or format, as long as you give appropriate credit to the original author(s) and the source, provide a link to the Creative Commons licence, and indicate if changes were made. The images or other third party material in this article are included in the article's Creative Commons licence, unless indicated otherwise in a credit line to the material. If material is not included in the article's Creative Commons licence and your intended use is not permitted by statutory regulation or exceeds the permitted use, you will need to obtain permission directly from the copyright holder. To view a copy of this licence, visit http://creativecommons.org/licenses/by-nc/4.0/.

\section{References}

1. Raffaelli B, Reuter U. The biology of monoclonal antibodies: focus on calcitonin gene-related peptide for prophylactic migraine therapy. Neurotherapeutics. 2018;15(2):324-35.

2. Tepper SJ. History and review of anti-calcitonin gene-related peptide (CGRP) therapies: from translational research to treatment. Headache. 2018;58(Suppl 3):238-75.

3. Silberstein SD, Marcus DA. Sumatriptan: treatment across the full spectrum of migraine. Expert Opin Pharmacother. 2013;14(12):1659-67.

4. Ashkenazi A, Blumenfeld A. OnabotulinumtoxinA for the treatment of headache. Headache. 2013;53(Suppl 2):54-61.

5. American Headache Society. The American Headache Society position statement on integrating new migraine treatments into clinical practice. Headache. 2019;59(1):1-18.

6. GBD 2016 Disease and Injury Incidence and Prevalence Collaborators. Global, regional, and national incidence, prevalence, and years lived with disability for 328 diseases and injuries for 195 countries, 1990-2016: a systematic analysis for the Global Burden of Disease Study 2016. Lancet. 2017;390(10100):1211-59.

7. Lipton RB, Bigal ME, Diamond M, et al. Migraine prevalence, disease burden, and the need for preventive therapy. Neurology. 2007;68(5):343-9.

8. Serrano D, Lipton RB, Scher AI, et al. Fluctuations in episodic and chronic migraine status over the course of 1 year: implications for diagnosis, treatment and clinical trial design. J Headache Pain. 2017;18(1): 101

9. Headache Classification Committee of the International Headache Society (IHS). The International Classification of headache disorders, 3rd edition. Cephalalgia. 2018;38(1):1-211.

10. Bigal ME, Serrano D, Buse D, et al. Acute migraine medications and evolution from episodic to chronic migraine: a longitudinal population-based study. Headache. 2008;48(8):1157-68.

11. Katsarava Z, Schneeweiss S, Kurth T, et al. Incidence and predictors for chronicity of headache in patients with episodic migraine. Neurology. 2004;62(5):788-90.

12. Lipton RB, Fanning KM, Serrano D, et al. Ineffective acute treatment of episodic migraine is associated with new-onset chronic migraine. Neurology. 2015;84(7):688-95.

13. Scher AI, Stewart WF, Ricci JA, et al. Factors associated with the onset and remission of chronic daily headache in a populationbased study. Pain. 2003;106(1-2):81-9.

14. Scher AI, Midgette LA, Lipton RB. Risk factors for headache chronification. Headache. 2008;48(1):16-25.

15. Agosti R. Migraine burden of disease: from the patient's experience to a socio-economic view. Headache. 2018;58(Suppl 1):17-32.

16. Rendas-Baum R, Yang M, Varon SF, et al. Validation of the Headache Impact Test (HIT-6) in patients with chronic migraine. Health Qual Life Outcomes. 2014;12:117.

17. Yang M, Rendas-Baum R, Varon SF, et al. Validation of the Headache Impact Test (HIT-6) across episodic and chronic migraine. Cephalalgia. 2011;31(3):357-67.

18. Lipton RB, Stewart WF, Sawyer J, et al. Clinical utility of an instrument assessing migraine disability: the Migraine Disability Assessment (MIDAS) questionnaire. Headache. 2001;41(9):854-61.

19. Stewart WF, Lipton RB, Dowson AJ, et al. Development and testing of the Migraine Disability Assessment (MIDAS) Questionnaire to assess headache-related disability. Neurology. 2001;56(6 Suppl 1):S20-8.

20. Martin BC, Pathak DS, Sharfman MI, et al. Validity and reliability of the migraine-specific quality of life questionnaire (MSQ Version 2.1). Headache. 2000;40(3):204-15. 
21. Hareendran A, Mannix S, Skalicky A, et al. Development and exploration of the content validity of a patient-reported outcome measure to evaluate the impact of migraine: the migraine physical function impact diary (MPFID). Health Qual Life Outcomes. 2017;15(1):224.

22. Kawata AK, Hareendran A, Shaffer S, et al. Evaluating the psychometric properties of the Migraine Functional Impact Questionnaire (MFIQ). Headache. 2019;59(8):1253-69.

23. Hareendran A, Skalicky A, Mannix S, et al. Development of a new tool for evaluating the benefit of preventive treatments for migraine on functional outcomes: the Migraine Functional Impact Questionnaire (MFIQ). Headache. 2018;58(10):1612-28.

24. US Department of Health and Human Services Food and Drug Administration. Guidance for Industry. Patient-reported outcome measures: use in medical product develpment to support labeling claims. US Department of Health and Human Services Food and Drug Administration. https://www.fda.gov/media/77832/downl oad. Accessed 24 Aug 2020.

25. Buse D, Manack A, Serrano D, et al. Headache impact of chronic and episodic migraine: results from the American Migraine Prevalence and Prevention study. Headache. 2012;52(1):3-17.

26. Blumenfeld AM, Varon SF, Wilcox TK, et al. Disability, HRQoL and resource use among chronic and episodic migraineurs: results from the International Burden of Migraine Study (IBMS). Cephalalgia. 2011;31(3):301-15.

27. Adams AM, Serrano D, Buse DC, et al. The impact of chronic migraine: the Chronic Migraine Epidemiology and Outcomes (CaMEO) study methods and baseline results. Cephalalgia. 2015;35(7):563-78.

28. Buse DC, Scher AI, Dodick DW, et al. Impact of migraine on the family: perspectives of people with migraine and their spouse/domestic partner in the CaMEO study. Mayo Clin Proc. 2016;91(5):596-611.

29. Lipton RB, Munjal S, Alam A, et al. Migraine in America Symptoms and Treatment (MAST) study: baseline study methods, treatment patterns, and gender differences. Headache. 2018;58(9):1408-26.

30. Lipton RB, Tepper SJ, Reuter U, et al. Erenumab in chronic migraine: patient-reported outcomes in a randomized double-blind study. Neurology. 2019;92(19):e2250-60.

31. Migraine Research Foundation. About migraine: migraine facts. https://migraineresearchfoundation.org/about-migraine/migrainefacts/. Accessed 3 Oct 2019.

32. Bonafede M, Sapra S, Shah N, et al. Direct and indirect healthcare resource utilization and costs among migraine patients in the United States. Headache. 2018;58(5):700-14.

33. Buse DC, Yugrakh MS, Lee LK, et al. Burden of illness among people with migraine and $\geq 4$ monthly headache days while using acute and/or preventive prescription medications for migraine. $\mathrm{J}$ Manag Care Spec Pharm. 2020;26(10):334-43.

34. Diamond S, Bigal ME, Silberstein S, et al. Patterns of diagnosis and acute and preventive treatment for migraine in the United States: results from the American Migraine Prevalence and Prevention study. Headache. 2007;47(3):355-63.

35. Lipton RB, Serrano D, Holland S, et al. Barriers to the diagnosis and treatment of migraine: effects of sex, income, and headache features. Headache. 2013;53(1):81-92.

36. Dodick DW, Loder EW, Manack Adams A, et al. Assessing barriers to chronic migraine consultation, diagnosis, and treatment: results from the Chronic Migraine Epidemiology and Outcomes (CaMEO) study. Headache. 2016;56(5):821-34.

37. Buse DC, Lipton RB, Hallstrom Y, et al. Migraine-related disability, impact, and health-related quality of life among patients with episodic migraine receiving preventive treatment with erenumab. Cephalalgia. 2018;38(10):1622-31.
38. Rome T. FDA warning label for otc migraine medications long overdue. The Headache Pros, Inc. https://migrainedisease.org/ news/fda-warning-label-for-otc-migraine-medications-long-overd ue. Accessed 28 Aug 2020.

39. Ashina S, Foster SA, Nicholson RA, et al. Opioid use among people with migraine: results of the OVERCOME study [abstract no. OR10]. Headache. 2019;59(Suppl 1):11.

40. Bickel J, Connelly M, Glynn EF, et al. Rates and predictors of using opioids in the emergency department to treat migraine in adolescents and young adults [abstract no. OR11]. Headache. 2019;59(Suppl 1):12.

41. Depakote (divalproex sodium): US prescribing information. North Chicago, IL: AbbVie Inc.; 2020.

42. Trokendi XR (topiramate extended-release): US prescribing information. Rockville, MD: Supernus Pharmaceuticals; 2020.

43. Inderal (propranolol): US prescribing information. New York, NY: Pfizer; 2017.

44. Istalol (timolol maleate ophthalmic solution): US prescribing information. Bridgewater, NJ: Bausch + Lomb; 2013.

45. Aimovig (erenumab-aooe): US prescribing information. Thousand Oaks, CA: Amgen Inc.; 2020.

46. Emgality (galcanezumab-gnlm): US prescribing information. Indianapolis, IN: Eli Lilly and Company; 2019.

47. Ajovy (fremanezumab-vfrm): US prescribing information. North Wales, PA: Teva Pharmaceuticals USA, Inc; 2020.

48. Vyepti (eptinezumab-jjmr): US prescribing information. Bothell, WA: Lundbeck Seattle BioPharmaceuticals, Inc.; 2020.

49. Botox (onabotulinumtoxinA): US prescribing information. Irvine, CA: Allergan, Inc.; 2020.

50. Depacon (valproate sodium): US prescribing information. North Chicago, IL: AbbVie Inc.; 2020.

51. Lopressor (metoprolol tartrate): US prescribing information. Cambridge, MA: Novartis; 2008.

52. Elavil (amitriptyline hydrochloride): US prescribing information. Princeton, NJ: Sandoz US; 2014.

53. Effexor XR (venlafaxine extended-release): US prescribing information. Philadelphia, PA: Wyeth Pharmaceuticals LLC.; 2018.

54. Tenormin (atenolol): US prescribing information. Pine Brook, NJ: Almatica Pharma, Inc; 2017.

55. Corgard (nadolol): US prescribing information. Louisville, KY: US WorldMeds, LLC; 2019.

56. Schwedt TJ. Preventive therapy of migraine. Continuum (Minneap Minn). 2018;24(4, Headache):1052-65.

57. Silberstein SD. Practice parameter: evidence-based guidelines for migraine headache (an evidence-based review): report of the Quality Standards Subcommittee of the American Academy of Neurology. Neurology. 2000;55(6):754-62.

58. Blumenfeld AM, Bloudek LM, Becker WJ, et al. Patterns of use and reasons for discontinuation of prophylactic medications for episodic migraine and chronic migraine: results from the second International Burden of Migraine Study (IBMS-II). Headache. 2013;53(4):644-55.

59. Bonafede M, Wilson K, Xue F. Long-term treatment patterns of prophylactic and acute migraine medications and incidence of opioid-related adverse events in patients with migraine. Cephalalgia. 2019;39(9):1086-98.

60. Edvinsson L. The trigeminovascular pathway: role of CGRP and CGRP receptors in migraine. Headache. 2017;57(Suppl 2):47-55.

61. Zhang Z, Winborn CS, de Prado MB, et al. Sensitization of calcitonin gene-related peptide receptors by receptor activitymodifying protein-1 in the trigeminal ganglion. J Neurosci. 2007;27(10):2693-703.

62. Hansen JM, Hauge AW, Olesen J, et al. Calcitonin gene-related peptide triggers migraine-like attacks in patients with migraine with aura. Cephalalgia. 2010;30(10):1179-86. 
63. Juhasz G, Zsombok T, Modos EA, et al. NO-induced migraine attack: strong increase in plasma calcitonin gene-related peptide (CGRP) concentration and negative correlation with platelet serotonin release. Pain. 2003;106(3):461-70.

64. Juhasz G, Zsombok T, Jakab B, et al. Sumatriptan causes parallel decrease in plasma calcitonin gene-related peptide (CGRP) concentration and migraine headache during nitroglycerin induced migraine attack. Cephalalgia. 2005;25(3):179-83.

65. Holland PR, Goadsby PJ. Targeted CGRP small molecule antagonists for acute migraine therapy. Neurotherapeutics. 2018;15(2):304-12.

66. Ubrelvy (ubrogepant): US prescribing information. Madison, NJ: Allergan USA, Inc.; 2020.

67. Nurtec ODT (rimegepant): US prescribing information. New Haven, CT: Biohaven Pharmaceuticals; 2020.

68. Hargreaves R, Olesen J. Calcitonin gene-related peptide modulators: the history and renaissance of a new migraine drug class. Headache. 2019;59(6):951-70.

69. Goadsby PJ, Reuter U, Hallstrom Y, et al. A controlled trial of erenumab for episodic migraine. N Engl J Med. 2017;377(22):2123-32.

70. Stauffer VL, Dodick DW, Zhang Q, et al. Evaluation of galcanezumab for the prevention of episodic migraine: the EVOLVE-1 randomized clinical trial. JAMA Neurol. 2018;75(9):1080-8.

71. Ashina M, Saper J, Cady R, et al. Eptinezumab in episodic migraine: a randomized, double-blind, placebo-controlled study (PROMISE-1). Cephalalgia. 2020;40(3):241-54.

72. Tepper S, Ashina M, Reuter U, et al. Safety and efficacy of erenumab for preventive treatment of chronic migraine: a randomised, double-blind, placebo-controlled phase 2 trial. Lancet Neurol. 2017;16(6):425-34.

73. Detke HC, Goadsby PJ, Wang S, et al. Galcanezumab in chronic migraine: the randomized, double-blind, placebo-controlled REGAIN study. Neurology. 2018;91(24):e2211-21.

74. Silberstein SD, Dodick DW, Bigal ME, et al. Fremanezumab for the preventive treatment of chronic migraine. N Engl J Med. 2017;377(22):2113-22.

75. Lipton RB, Goadsby PJ, Smith J, et al. Efficacy and safety of eptinezumab in patients with chronic migraine: PROMISE-2. Neurology. 2020;94(13):e1365-77.

76. Silberstein SD, Holland S, Freitag F, et al. Evidence-based guideline update: pharmacologic treatment for episodic migraine prevention in adults: report of the Quality Standards Subcommittee of the American Academy of Neurology and the American Headache Society. Neurology. 2012;78(17):1337-45.

77. Marmura MJ, Silberstein SD, Schwedt TJ. The acute treatment of migraine in adults: the American Headache Society evidence assessment of migraine pharmacotherapies. Headache. 2015;55(1):3-20.
78. Reyvow (lasmiditan): US prescribing information. Indianapolis, IN: Eli Lily and Company; 2020.

79. Manolakis PG, Skelton JB. Pharmacists' contributions to primary care in the United States collaborating to address unmet patient care needs: the emerging role for pharmacists to address the shortage of primary care providers. Am J Pharm Educ. 2010;74(10):S7.

80. Wenzel RG, Lipton RB, Diamond ML, et al. Migraine therapy: a survey of pharmacists' knowledge, attitudes, and practice patterns. Headache. 2005;45(1):47-52.

81. 2020 Pharmacy Times survey of pharmacists' OTC recommendations: headache products. MJH Life Sciences and Contemporary Clinic. https://www.contemporaryclinic.com/otcguide/paininflam mation/headache-products. Accessed 26 Aug 2020.

82. 2020 Pharmacy Times survey of pharmacists' OTC recommendations: migraine headache products. MJH Life Sciences and Contemporary Clinic. https://www.contemporaryclinic.com/otcguide/ paininflammation/migraine-headache-products. Accessed 26 Aug 2020.

83. Wenzel RG, Padiyara RS, Schommer JC. Didactic migraine education in US doctor of pharmacy programs. Am J Pharm Educ. 2010;74(1):4.

84. Baratta F, Allais G, Rolando S, et al. Prevention, education and counselling: the worldwide role of the community pharmacist as an epidemiological sentinel of headaches. Neurol Sci. 2019;40(Suppl 1):15-21.

85. Brusa P, Allais G, Scarinzi C, et al. Self-medication for migraine: a nationwide cross-sectional study in Italy. PLoS ONE. 2019;14(1):e0211191.

86. Wenzel RG, Sarvis CA, Krause ML. Over-the-counter drugs for acute migraine attacks: literature review and recommendations. Pharmacotherapy. 2003;23(4):494-505.

87. Giaccone M, Baratta F, Allais G, et al. Prevention, education and information: the role of the community pharmacist in the management of headaches. Neurol Sci. 2014;35(Suppl 1):1-4.

88. Wenzel RG. Migraine-preventive medications: ensuring their appropriate use. J Am Pharm Assoc (2003). 2008;48(5):e107-20.

89. Schwedt T, Reuter U, Tepper S, et al. Early onset of efficacy with erenumab in patients with episodic and chronic migraine. J Headache Pain. 2018;19(1):92.

90. Lipton RB, Munjal S, Buse DC, et al. Unmet acute treatment needs from the 2017 Migraine in America Symptoms and Treatment study. Headache. 2019;59(8):1310-23.

91. Murray KA, O’Neal KS, Weisz M. Dietary suggestions for migraine prevention. Am J Health Syst Pharm. 2015;72(7):519-21.

92. Hoffmann W, Herzog B, Muhlig S, et al. Pharmaceutical care for migraine and headache patients: a community-based, randomized intervention. Ann Pharmacother. 2008;42(12):1804-13. 